\title{
Article
}

\section{Transparency of Assessment in Practice Environments. An extension of the TAPE Model}

\author{
Stone, Clare
}

Available at http://clok.uclan.ac.uk/26532/

Stone, Clare ORCID: 0000-0001-7331-4244 (2019) Transparency of Assessment in Practice Environments. An extension of the TAPE Model. The Journal of Practice Teaching and Learning, 16 (1). ISSN 1759-5150

It is advisable to refer to the publisher's version if you intend to cite from the work. http://dx.doi.org/10.1921/jpts.v16i1.1249

For more information about UCLan's research in this area go to http://www.uclan.ac.uk/researchgroups/ and search for < name of research Group>.

For information about Research generally at UCLan please go to http://www.uclan.ac.uk/research/

All outputs in CLoK are protected by Intellectual Property Rights law, including Copyright law. Copyright, IPR and Moral Rights for the works on this site are retained by the individual authors and/or other copyright owners. Terms and conditions for use of this material are defined in the policies page.

\section{CLoK}

Central Lancashire online Knowledge www.clok.uclan.ac.uk

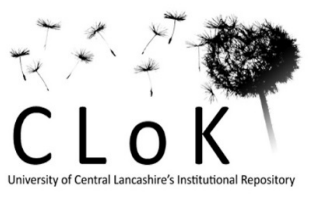




\title{
Transparency of Assessment in Practice Environments. An extension of the
}

\section{TAPE Model}

\begin{abstract}
Following research into UK social work students' experiences of assessment, Stone (2018) concluded that not all students appeared to be aware of who contributed towards their assessment nor what constituted reasonable assessment practice. The Transparency of Assessment in Practice Education (TAPE) Model was offered to the practice learning community as a tool to engage academics, practice educators and students in dialogue about assessment during placements. The purpose of the TAPE model is for all stakeholders to explore expectations to avoid misunderstandings and ambiguity about assessment. This article explores the potential use of the model within wider contexts of learning and assessment including the assessment of the users of services. The wider application of this innovative model suggests a name change to Transparency of Assessment in Practice Environments.
\end{abstract}

Key words: Assessment, Social Work, practice learning, placement, practice education 


\section{Transparency of Assessment in Practice Environments. An extension of the}

TAPE Model

\section{Introduction}

Many training and educational programmes require learners to spend time within the workplace and this is referred to by several terms including practice placement, practice learning opportunity, field education and structured work experience. There are a range of people within the workplace who support, teach and assess the learner and field educator, supervisor and practice educator are examples of the titles used for the person who takes the main responsibility for overseeing the experience. Placement and practice educator are used initially within this paper because they are current terms within social work education in England. Assessor and assessed are later adopted to reflect multi professional and wider contexts in which assessments take place in education and within professional practice.

As is the case in other professions, the placement component within UK social work education counts towards the overall assessment that the individual is 'fit to practise' and eligible to apply to join the professional register HCPC (2012:4). Therefore, the practice educator, in partnership with the Higher Educational Institution, is situated as important in the training and gatekeeping for the social work profession to ensure that only those suitable graduate (Bogo, Regehr, Hughes, Power, \& Gioberman, 2002; Miller \& Koerin, 2001). Research conducted by Stone (2018) highlighted a lack of clarity in relation to student understanding of placement assessment, with some students articulating negative experiences of assessment (Stone, 2018). Good practice requires that 'students must know what is to be assessed and how it will be evaluated' (Parker, 2010a:102) and where assessment is considered to be fair, collaborative and transparent there is a positive impact on the 
relationship with the assessor (Lefevre, 2005). The Transparency of Assessment in Practice Education (TAPE) Model was designed to offer clarity to students in relation to why they are assessed, who assesses them, when they are assessed, where assessment takes place, what is assessed and the way that they are assessed. The TAPE model brings together these six Ws of assessment; why, when, who, what, where, and way, within a simple diagram (see diagram 1). The model is intended to be used as a visual tool to facilitate dialogue between the student and the practice educator in order that the multifaceted activity of assessment is explicit and unambiguous, and for the student to experience assessment as fair, valid and reliable (Furness \& Gilligan, 2004).

Put Diagram 1 near here

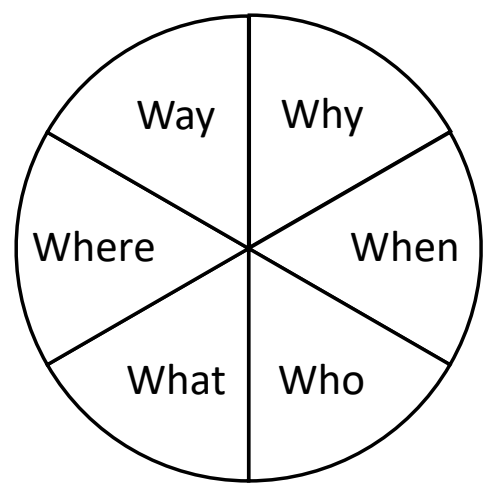

This article encourages the reader to consider the potential value of the TAPE model within wider contexts of learning, professional development and also within the practice of assessing the users of services. Because the model works to aid clarity to a wide range of assessment situations it may have merit across different disciplines, settings and countries. In addition to making assessment less ambiguous the model can also be used to negotiate the practice of assessment and thereby enact the principles of person centred practice with patients and the users of services. However, the act of drawing attention to the domains of assessment can have negative consequences and consideration is given to the support needs of the assessed 
and assessor. Because of the diverse settings that the model may be used in, it is suggested that the E in TAPE is changed from 'education' to 'environments'. From henceforth TAPE is short hand for Transparency of Assessment in Practice Environments.

\section{Using the TAPE model}

Readers are encouraged to draw upon the principles of the TAPE model to add clarity to their own assessment practises within professional learning and development and other situations of assessment. Diagram 1 shows the six Ws in a wheel formation and the assessor and assessed use the words to stimulate discussion about their understanding and expectations in relation to each aspect of assessment. However, the TAPE Model can be creatively adapted to meet the unique needs of the assessment situation or activity. For example, before a learning placement commences, students and practice educators can come together in a world café activity at the university. Six stations are set up in a room with each having a different one of the six Ws written on a large sheet of paper. The practice educators and students move around the room and exchange ideas and thoughts about the $\mathrm{W}$ in front of them. They ought to be encouraged to draw and make notes on the paper, but the main aim is collaborative learning where they share their expectations and anxieties about assessment. A debriefing and concluding session to this activity is essential.

The TAPE model can be introduced to students within the university setting in advance of the placement commencing and the practice educator can use the same framework throughout the placement period to ensure the learner continues to be aware and familiar with the process of assessment. There are opportunities at the preplacement visit, learning agreements, formal reviews and tutor visits for the TAPE model to be used to facilitate discussion about assessment. In one to one supervision sessions the TAPE wheel can be drawn on paper and 
the practice educator can invite the student to consider each of the Ws in turn. Both parties can write or draw on the paper and discuss thoughts and feelings. This is also an appropriate opportunity to agree how the voices of service users will be meaningfully obtained and how their feedback will be used to support critical reflection (Beresford, 2013). Both parties can negotiate how formative feedback will be generated from a range of stakeholders and incorporated to shape learning and development (Finch, 2017; Ketner, VanCleave, \& CooperBolinskey, 2017; Williams \& Rutter, 2010). Maintaining focus on the domains of assessment throughout the placement creates opportunity to consider and arrange additional learning opportunities and support to give the student a valuable learning experience. Diagram two is designed to be used to remind practice educators about the factors which underpin the six Ws in relation to social work students. Practitioners and educators from professions other than social work may wish to design their own prompts and share this amongst their professional community. 
Way: Performance evidence (what is seen)

and capability evidence (what is implied

through behaviour, written work and

Why: Formative to shape

conversation). Includes formal and informal

learning opportunities,

observation, feedback, supervision and

support and development.

role-plav.

Where: Every place including service users' homes, community settings, online, social media, office, social meetings spaces and supervision.
What: Everything including behaviour, spoken word, writing, nonverbal, relationships, emotional competence, approach to learning, motivation, time keeping and resilience.
Summative end point assessment.

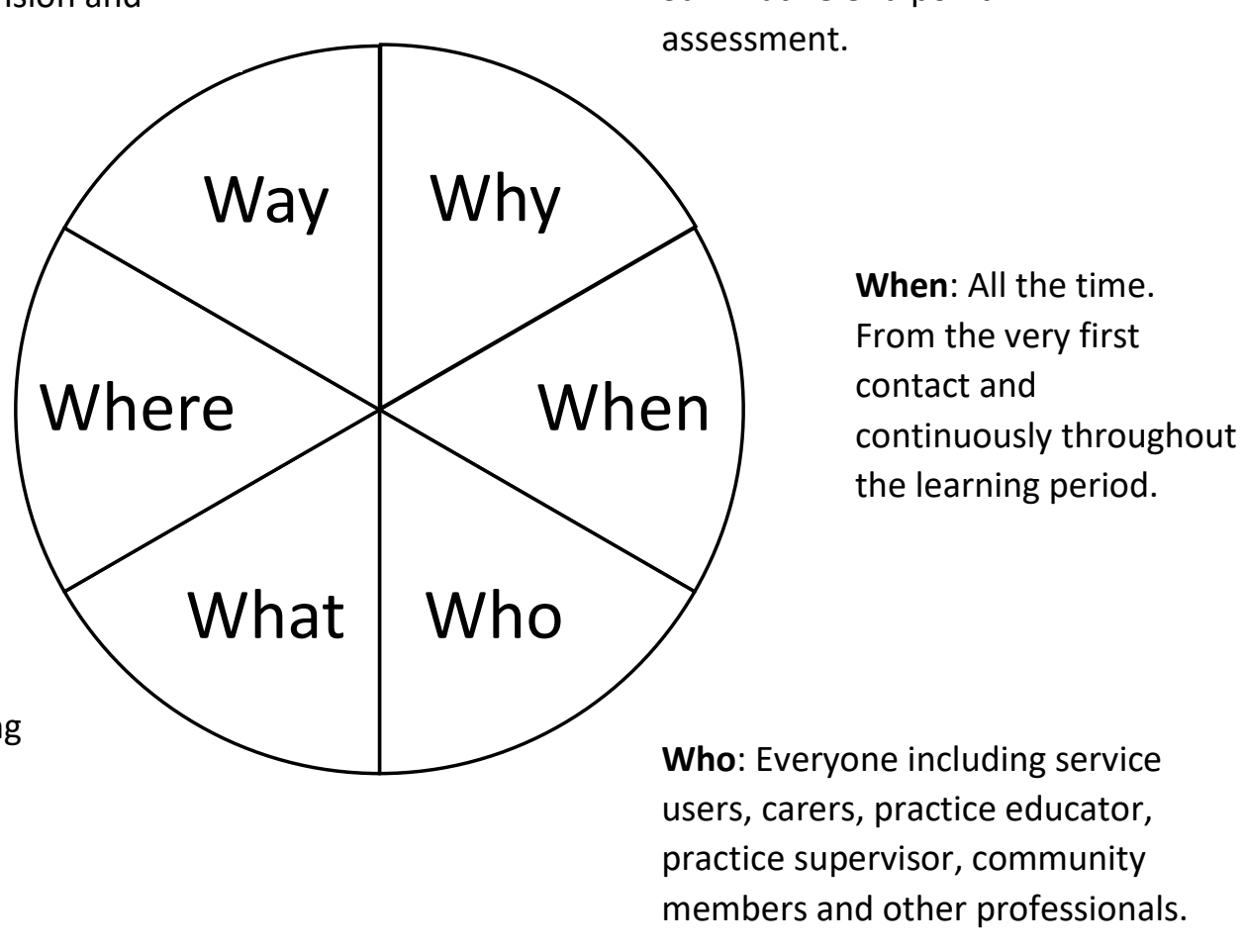

The TAPE model can also be used in classroom based learning with either children or adults.

The principles can be used for the assessment of presentations, simulated activities and roleplay to enable those being assessed to be explicitly clear about the structure of assessment. The Objective Structured Clinical Examination (OSCE) assesses healthcare professional clinical skills through interaction with simulated patients (Zayyan, 2011) and has recently been used to assess the competence of social work practitioners (D.F.E., 2017).

Zayyan (2011) advises that OSCE actors require careful training and the TAPE model may be used to prepare them, prepare the assessor and the person being assessed so they are all clear about their role, remit and understand the formulaic marking matrix. 
Sharing the TAPE model with practice educators in the UK has generated many helpful suggestions as to how the model can be used in practice and has inspired the writing of this article. One such recommendation is that the most logical place to start is at 'why'. This is because the person being assessed needs to understand there will be a summative judgement about competence and capability, but there may also be formative aspects meaning that assessment is continuous, ongoing and designed to guide learning and development (Beverley \& Worsley, 2007; Biggs \& Tang, 2007).

The principles of TAPE are useful during the probation period of new staff members, to structure appraisals and during the Assessed and Supported Year in Employment of newly qualified Social Workers. The model has the potential to be used within any assessment relationship, in any discipline and in any country. Social work practitioners have advised that the principles of TAPE can also be used in their practice with the users of their service. They suggest that practitioners undertaking assessment can draw upon the TAPE model to explain assessment and where appropriate they can even negotiate with service users / patients / clients the process by which they will be assessed. The principles of TAPE may encourage the practitioner to reflect upon their role within the assessment and help the individual being assessed to understand:

- Why assessment is taking place (to safeguard and protect, to diagnose or to assess need to inform the commissioning of services)?

- When is the most appropriate time to assess so that a reliable picture is formed of the individual's strengths, abilities and needs? Are there timeframes imposed directing when the assessment is to be complete or can this be negotiated?

- Who will be involved in the assessment, whose voice will be heard and how will that be represented within the assessment? There is an opportunity here to consider the 
power dynamics at play and also who can support each person involved in the assessment.

- What is assessed and is considered of importance and of relevance to that particular assessment? Including what is not considered of importance and assessable.

- Where will the assessment take place? This is an opportunity to consider environmental factors, access and resources.

- The way an individual is assessed must be designed to measure that which is intended. It is good practice to enable the assessed individual to be involved in designing the way the assessment is conducted. In what way will the outcome of the assessment be communicated?

Wilkins (2015:13) described the assessment of his family as 'intensively emotional and highly stressful' and his narrative illustrates how he lacked insight into the six Ws of assessment. The why of assessment began to concern Wilkins because he felt that if he and his wife came across as too capable the family would 'be denied' support, yet worried that their parenting capacity would be questioned if he 'presented things as too hard' (Wilkins, 2015:14). He explained that the pace of the assessment was dictated by the worker's timetable and he did not feel empowered to disclose information when he and his family felt ready. There was lack of discussion and agreement in relation to who was involved in the assessment and other professionals were spoken to without his 'consent' and meetings were held to which he nor his children were invited (Wilkins, 2015:14). Wilkins did not know what assessment activities were being employed and this led to mistrust and concerns of negative surveillance which resonate with the findings of Stone in her research of students on placement (Stone, 2018).

Using the six Ws of the TAPE model may have empowered Wilkins and his wife to share 
their lived experience and supported them to co-produce a reliable assessment rather than them having 'the sense of being surveyed' (Wilkins, 2015:14). Acknowledging issues of power within assessment creates opportunity for more 'open and honest relationships' (Parker, 2010b:996). Wilkins himself concludes that:

One relatively simple way of improving our experience would have been for more time to be spent explaining the purpose of different questions, tasks and activities but also a more flexible approach to assessment in general. (Wilkins, 2015:14)

It is imperative to highlight that good assessment practice will exist within social work, social care, education and healthcare. However even within positive encounters, there may be opportunities for the practitioner and multidisciplinary team to reflect upon their assessment practice and work to further empower those being assessed. 'To effect full and genuine participation, therefore, practitioners need to think carefully about their decision-making processes and the balance of power that exists' (Warren, 2007 50). In the spirit of representing voice, sharing power, person centred practice and coproduction, the TAPE model is best used in partnership with those who use services (Lynch, 2014). Nothing about the individual 'should be uncovered, sifted, discussed, concluded and written down without their participation and knowledge' (Martin, 2010:11). The individual or family can be empowered to direct the assessment process and make decisions about whose voice in addition to their own is heard, how it is heard, when they are assessed and in what environments. Other than in life saving situations or where statutory duties direct the assessment process, practitioners can use the model to offer the assessed person control and choice within the assessment practice.

\section{A note of caution}

The Transparency of Assessment in Practice Environments Model is designed to draw 
attention to the domains of assessment in order that the assessed and the assessor can reflect upon the process and where appropriate they can negotiate and work together thereby avoiding ambiguity and mistrust. However, making the elements of assessment more explicit and obvious can increase anxiety in the person being assessed (Stone, 2018).

People do not learn when they are fearful, so it is therefore essential that you are able to create a culture of learning and model practice which shows how mistakes can be learnt from and feedback is helpful (Nicholas \& Kerr, 2015:40)

Thompson (2006) offers a learning continuum with total ease and complacency at one end and the other is characterised by panic, loss of control and feeling overwhelmed. He advises 'that each of the two extremes minimises learning' and thereby creating an environment within the middle ground on the continuum is desired (Thompson, 2006:102).

By drawing more attention to assessment and returning to it throughout the assessment period has the potential to create more anxiety in those being assessed whether they are learners or the users of services. Exposing individuals to the idea that everyone they meet may be involved in their assessment, that everything they say and do, even things they do not say and do not do is assessable, and that assessment takes place in every space they inhibit could exacerbate feelings of nervousness which can impact on ability and behaviour. This can compromise the assessment experience and the assessment outcome therefore the manner in which the six domains of assessment are presented and discussed are important to maximise understanding yet minimise negative outcomes.

Although a wide range of stakeholders ought to be invited to provide feedback it may be appropriate to consider the context in which it is requested and presented. A practitioner can demonstrate high level skills yet the feedback suggests poor practice because the patient did not receive the outcome/diagnosis/service they hoped for. Likewise, very positive feedback 
may be received but the practitioner may not have followed guidance and their practice was dangerous. Questionnaires (paper, online or verbal) ought to align to the intended learning outcomes in order that the feedback becomes a more reliable assessment of competence in practice. Some individuals may be reluctant or unable to offer feedback whilst the 'vocal minority' tend to have a dominant voice (Beresford, 2013:5). Including feedback from a wide range of stakeholders is important but feedback overload can arise and the assessed and assessor need to take into account volume, timing and whose voice is represented.

Making mistakes is part of life and learning, and the TAPE model is not intended to be a threatening or punitive tool. Individuals need safe spaces to live, learner, grow and develop. Although the six Ws can cover all behaviours and values, exceeding one's remit and power as an assessor is not the intention of this model. The principles of why assessment is taking place and what is being assessed need to be clearly understood. Therefore the TAPE model can be used in the training of assessors to ensure they understand their role, the purpose of assessment and the power dynamics at play. Not all assessors feel comfortable in exercising their power to the extent that some fail to fail students. Poor assessment outcomes predominantly related to inconsistent grading, uncertainty and lack of confidence which ultimately lead to ethical issues in relation to failure to gate keep for the profession (Bush, Schreiber, \& Oliver, 2013; Docherty, 2018; Finch \& Parker, 2013; Finch \& Taylor, 2012). In addition to failing to address concern, is potential for assessors to make hasty decisions or focus on negative indicators which are beyond the remit of the assessment. The individual being assessed may have concerns that unrelated and irrelevant factors are unfairly included in assessment decisions. The TAPE model is a useful tool in the training of assessors and to assist in the management of situations of conflict. The model can be used as a mediation tool allowing both parties to share their expectations, unique perspectives and experience. During 
situations of conflict the six Ws offer structure to debate issues and become a framework for resolution through renegotiation. It is suggested that the TAPE model is introduced at the outset of the assessment relationship to ensure that all parties are clear about the assessment practices, duration and composition of assessment. And the TAPE model is revisited throughout the learning period not to add pressure, but to mitigate against the many challenges of undertaking assessment.

Although the original model advises that formative assessment identifies support needs, the model does not draw adequate attention to the type of support required and available during the period of assessment. It is pertinent to ask the assessed what type of support they require and together consider how that will be provided. Likewise, the assessor may need to reflect upon the support available to themselves. The six Ws can be used as a framework to identify support during the assessment (see diagram 3):

- Why do you need support (what are the risks)

- When do you need support (are there specific periods of vulnerability)

- Who is the best person (or service) to offer that support and who is going to make the approach (a referral may be required)

- What specifically do you need support with, what are you requiring of the other person or service

- Where do you require support and where can this support be obtained (this may be physical resources, environments, places or time)

- In what way will this be provided, in what way will you recognise that support is meeting need. 


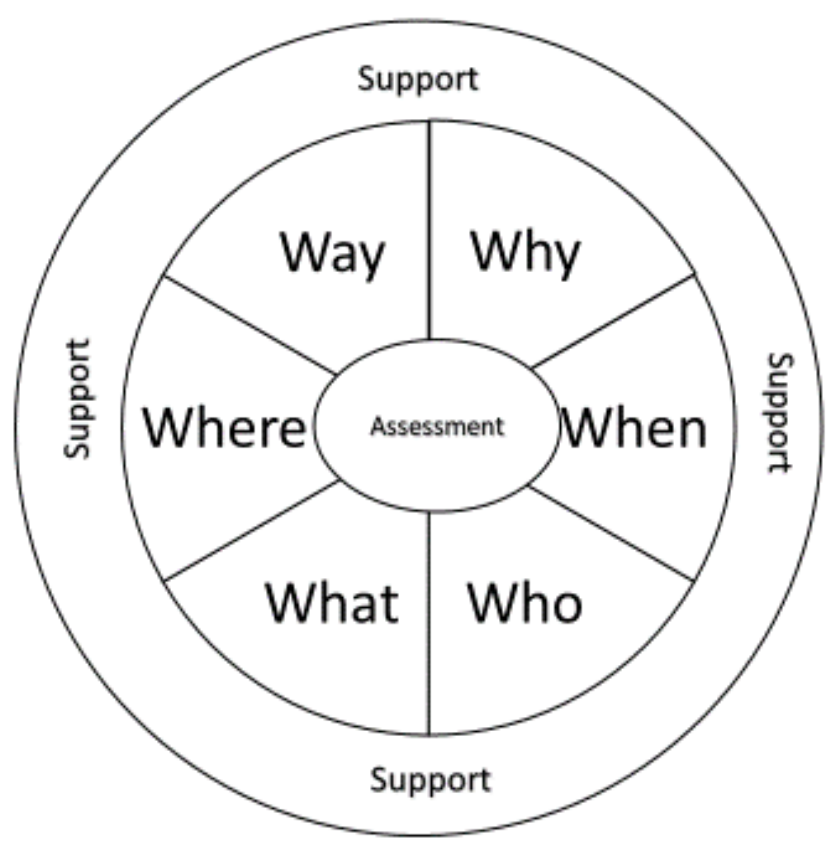

\section{Limitations}

The writing of this article has been inspired by the feedback received from social work practice educators and academics who have been introduced to the model for the first time or have started to use it in their practice and training. It is important to acknowledge that no formal evaluation of the model has taken place and the suggestions above are informed from the original empirical research (Stone, 2018) and from those within practice. The suggested applications of the model in wider professional context of education and practice are speculative. However, it is hoped that readers will feel inspired to reflect both upon their own assessment practice, the type of assessments they conduct and the assessment experiences of individuals and families.

\section{Conclusion}

The TAPE model was introduced to the social work practice learning community with the 
intention of making the domains of assessment clearer to students. Initial feedback suggests this model has been well received and has positive impact in terms of social work practice education in the UK. This article champions a wider application of the model by suggesting that the principles of TAPE may be of value internationally, for other professional learning and development contexts and even within professional practice. Practitioners in any country and from any discipline are encouraged to reflect upon the six domains of assessment to identify opportunities to use the principles of the TAPE model with anyone who is subject to assessment and this includes the users of services. By exploring why, when, who, what, where and the way of assessment, it is anticipated that service users, patients and clients will have a deeper level of understanding of the assessment they are subject to and in the spirit of person centred practice there may be opportunities to negotiate aspects of the assessment process. Educators and practitioners are encouraged to use this innovative model creatively to best fit their assessment situations. However, a note of caution is advised when using the TAPE model because by drawing more attention to assessment there is potential to exacerbate anxiety and nervousness. Therefore, careful attention is encouraged to identify and respond to the support needs of both the assessed and assessor throughout the period of assessment.

\section{Bibliography}

Beresford, P. (2013). Beyond the usual suspects. Towards inclusive user involvement. Practical guide. http://www.shapingourlives.org.uk/documents/BTUSGUIDE.pdf: Shaping Our Lives.

Beverley, A., \& Worsley, A. (2007). Learning and teaching in social work practice. Basingstoke: Palgrave Macmillan.

Biggs, J., \& Tang, C. (2007). Teaching for Quality Learning at University : What the Student Does (3rd Edition). Buckingham: Open University Press.

Bogo, M., Regehr, C., Hughes, J., Power, R., \& Gioberman, J. (2002). Evaluating A Measure Of Student Field Performance In Direct Service: Testing Reliability And Validity Of Explicit Criteria. Journal of Social Work Education, 38(3), 385-401. 
Bush, H. M., Schreiber, R., \& Oliver, S. J. (2013). Failing to fail: clinicians' experience of assessing underperforming dental students. European Journal of Dental Education, November 2013, Vol.17(4), 198-207.

D.F.E. (2017). Confidence in practice: child and family social work assessment and accreditation system Government consultation response Crown Copyright.

Docherty, A. (2018). Failing to Fail in Undergraduate Nursing: Understanding the Phenomenon. Nursing Education Perspectives; New York, 39(6), 335-342.

Finch, J. (2017). Supporting struggling students on placement. A practical guide. Bristol: Policy Press.

Finch, J., \& Parker, J. (2013). Editorial Special Issue 'Failing students'. The Journal of Practice Teaching and Learning, Volume 11, Number 3 3-7.

Finch, J., \& Taylor, I. (2012). Failure to Fail? Practice Educators' Emotional Experiences of Assessing Failing Social Work Students. Social Work Education: The International Journal, 32(2), 244258.

Furness, S., \& Gilligan, P. (2004). Fit for purpose: issues from practice placements, practice teaching and the assessment of students' practice. Social Work Education, 23(4), 465-479.

HCPC. (2012). An Introduction To Our Education Processes. In. London: Health and Care Professions Council.

Ketner, M., VanCleave, D., \& Cooper-Bolinskey, D. (2017). The Meaning and Value of Supervision in Social Work Field Education. Field Educator, 7.2 (Fall 2017), 1-18.

Lefevre, M. (2005). Facilitating Practice Learning and Assessment: The Influence of Relationship. Social Work Education, 24(5), 565-583. doi:10.1080/02615470500132806

Lynch, R. (2014). Social Work Practice with Older People. A positive person-centred approach. London: Sage.

Martin, R. (2010). Social work assessment. Exeter: Learning Matters.

Miller, J., \& Koerin, B. B. (2001). Gatekeeping in the Practicum: What Field Instructors Need to Know. Clinical Supervisor, 20(2), 1.

Nicholas, W. S., \& Kerr, J. (2015). Practice Educating Social Work Students. Supporting Qualifying Students on Their Placements. Maidenhead: Open University Press.

Parker, J. (2010a). Effective Practice Learning in Social Work (2nd ed.). Exeter: Learning Matters.

Parker, J. (2010b). When Things Go Wrong! Placement Disruption and Termination: Power and Student Perspectives. British Journal of Social Work, 40(3), 983-999. doi:10.1093/bjsw/ben149

Stone, C. (2018). Transparency of assessment in practice education: the TAPE model. Social Work Education, 1-18. doi:10.1080/02615479.2018.1475556

Thompson, N. (2006). Promoting Workplace Learning. Bristol: The Policy Press.

Warren, J. (2007). Service User and Carer Participation in Social Work. Exeter: Learning Matters.

Wilkins, D. (2015). The impact of 'being assessed' by a disabled children's team: a personal reflective account. Child \& Family Social Work, 20(1), 10-18. doi:10.1111/cfs.12026

Williams, S., \& Rutter, L. (2010). The practice educator's handbook Exeter : Learning Matters.

Zayyan, M. (2011). Objective structured clinical examination: the assessment of choice. Oman Medical Journal, 26(4), 219-222. 